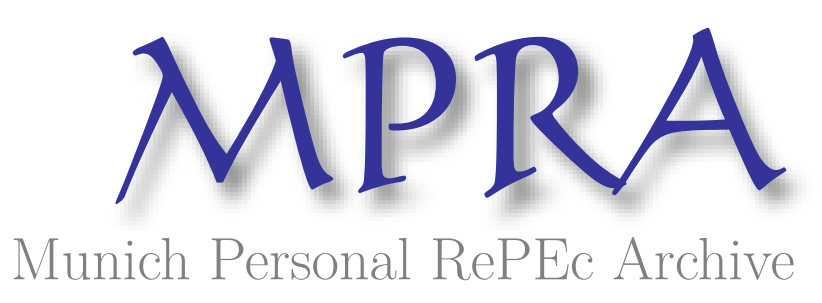

\title{
Incorporating inventories into supply and demand analysis
}

Sexton, Robert L. and Clower, Robert W. and Graves, Philip E. and Lee, Dwight R.

Pepperdine University, University of South Carolina, University of Colorado, University of Georgia

1992

Online at https://mpra.ub.uni-muenchen.de/19905/

MPRA Paper No. 19905, posted 11 Jan 2010 07:35 UTC 


\title{
Incorporating Inventories into Supply and Demand Analysis
}

\author{
ROBERT L. SEXTON, ROBERT W. CLOWER, PHILIP E. GRAVES, \\ AND DWIGHT R. LEE*
}

Standard accounts of supply and demand analysis at the principles and intermediate level courses are, for the most part, very misleading. In most of these courses, supply and demand is treated as a flow concept erroneously assuming that excess holder demand (i.e., excess stock demand) is always equal to zero. However, in order to gain a full understanding of business cycles, the distinction between stocks and flows in supply and demand is essential. Explicit analysis of saving, investment, and growth processes is possible only in the context of the stock-flow model. Hence, the terms "demand" and "supply" in the standard principles text may conceal as much as they reveal about forces governing market behavior.

The early works of Walras and other general equilibrium theorists concentrated on the existence and the stability of a market equilibrium price in pure stock models (where assets can only be traded for other assets), in pure flow models (where income can only be traded for other assets), or in pure flow models (where income can only be consumed). Later, Marshall and other partial equilibrium economists took stock-flow analysis a step further when they established the familiar trichotomy: the market, short-run, and long-run periods. This was done so economists could establish a framework to handle transitory savings and investment processes. But this analysis fell short of the mark. While changes in long-run supply to varying plant sizes were examined, changes in long-run demand induced by savings decisions of households were, for the most part, ignored.

In 1954, an explicit model of price determination in a stock-flow economy was published [Clower, 1954; Bushaw and Clower, 1957]. Additional contributions to stock-flow analysis followed [Ackley, 1983; Acchibald and Lipsey, 1958; Chase, 1963; Hadar, 1965; Harrison, 1980].

Since stock-flow analysis is ignored in most current textbooks, this paper is intended to provide an introduction to stock-flow analysis for those that find inventories sufficiently important. Many significant aspects of macroeconomics depend on stocks, especially when dealing with business cycles. Students would better understand the entire process of macroeconomics if stocks were introduced explicitly in ordinary supply and demand analysis. An understanding of this framework could open doors to important research in

\footnotetext{
*Pepperdine Unversity, University of South Carolina, University of Colorado, and University of Georgia. The authors are grateful to an anonymous referese for helpful comments.
} 
the area of asset holding, production, and consumption in dynamic models of market behavior.

The term "supply" may refer to either the quantity of the commodity in stock at any particular moment or the rate (or flow) at which it is currently being produced. Likewise, the term "demand" refers to either the quantity at a point in time, while a flow is a quantity per unit of time at a point in time.

Does it really matter all that much that household and business inventories are ignored and that trade proceeds as if such inventories did not exist? If inventories remain constant, it is not critical. However, if a real-world discussion of short-run disequilibrium is to be provided, inventory depletions or accretions cannot be ignored since these are known to be important sources of economic instability.

\section{Stocks, Flows, and Exchange}

\section{(A) Stock Demand and Supply}

Individuals may wish to hold some level of inventories for several reasons. For example, individuals might want to provide a reserve against future predicaments, to hold inventories as a hedge against inflation, or most importantly, holding inventories to avoid frequent small-lot exchange transactions. Business firms and households are conscious of the costs that can be avoided by holding relatively large average inventories and buying and selling relatively large lots.

An individual's willingness to hold stocks of any particular commodity will vary inversely with market price, ceteris paribus. The higher the price of a commodity, the greater the amount of wealth that commodity represents. And, any time wealth is used to replenish inventories, the opportunity to earn interest on that wealth or consume other goods is foregone. The cost is relatively greater for high-priced goods as compared to low-priced goods.

Hence, the stock demand for any given commodity is a decreasing function of its market price. The stock demand curve is drawn on the assumption that the values of all variables (e.g., income, household size, expected inflation, and technology) other than market price are held constant. If any of these values should change, the position of the stock demand curve would shift.

Unless a good is instantaneously consumed, a purchase implies a willingness to add to present inventory holdings. The desire to add to inventories under current market conditions is called "excess holder demand."

The quantity of a commodity actually held by individuals at any given moment of time is a legacy from the past. That is, at any moment of time, the aggregate stock cannot be changed. That is, the stock supply curve is a vertical line to indicate that the quantity of existing stocks is independent of current market price.

The quantity of a commodity demanded to hold at any moment will be equal to the quantity actually in existence only at one particular level of market price, namely, that level at which the stock demand curve intersects the vertical stock supply curve. At any other price, either stock demand will exceed stock supply (excess holder demand will be 
positive) or stock supply will exceed stock demand (excess holder demand will be negative). This difference between stock demand and supply implies a desire on the part of some individuals to alter their existing holdings at the current market price.

Items that generally lead to non-zero excess holder demand for firms and consumers are the stock the seller has on hand, the costs of sturage, perishability of the product, and expectations of future prices. For example, households will add to inventories if they expect future prices to rise, provided that costs of storage are available and the product is not highly perishable. Similarly, how long will a seller hold inventories of a particular crop if they are highly perishable?

\section{(B) Flow Demand and Supply}

If individual holders of a commodity wish to alter their current stock, they may proceed to do so by changing their present rate of consumption or production, or by changing their current market purchases or sales. As in the standard treatment of supply in principles texts, the flow demand curve represents the relation between market price and desired consumption, and the flow supply curve represents the relation between market price and desired production. In general, the position of the flow demand and supply curves will depend upon many factors (e.g., population, income, suppliers' input prices, technology, and so forth). The desired rate of consumption evidently will be equal to the desired rate of production only at one particular value of market price. At any other price, excess user demand will be positive or negative instead of zero.

At this point, one might be tempted to suppose that current market price determines excess user demand (i.e., flow excess demand) and that current market price must also govern the current rate of change of stock supply. This is not so. The rate of change of stock supply at any point in time depends not on desired but actual rates of production and consumption. The flow demand and supply curves do not, in themselves, reveal anything about actual rates of production and consumption. That is, as will become clear in the next section, market demand and supply curves are not the flow demand and supply curves just discussed. Only under conditions when there are no desired changes in stocks will the observed market curves correspond to the flow curves.

\section{Market Demand and Supply}

Again, it is important to emphasize that decisions about rates of production and consumption and desired holding of inventories are separate and distinct from decisions about quantities demanded for purchase or offered for sale. The laws of market exchange are related to, but not derivable from, the law of production and consumption. That is, supply is more than merely the horizontal summation of marginal cost of production schedules, and demand is more than merely the horizontal summation of individual consumption demands.

It is likely that the quantity of a commodity that individuals are willing to purchase depends on market price and current stocks held by prospective buyers. Similarly, quantities offered for sale depend on market price and on current stocks held by 
prospective sellers. The conventional definitions of market demand and supply are flawed by their failure to explicitly recognize these facts.

This difficulty can be remedied by supposing that market demand, measured as a flow, is an increasing function of (positive) excess user demand of all households and firms. Thus, if consumers want to increase their stocks, then they must increase their inflow by purchasing in the market more than they wish for current consumption. Thus, the market demand for any commodity is a function of its current market price and of stocks currently held by prospective purchasers of the commodity. Similarly, suppose that market supply, measured as a flow, is an increasing function of (negative) excess holder demand. For example, if businesses have too much stock in inventories, they will offer more for sale to increase their outflow. Therefore, the market supply of any commodity is a function of its current market price and of stocks currently held by prospective sellers of the commodity.

\section{Market Equilibrium}

Since market price tends to rise when a commodity is in excess demand and to decline when it is in excess supply, it might seem natural to suppose that market price will be stationary over time if market demand is equal to market supply. But this would be an error. This may be seen most easily by supposing that price at time $t=0$ is at say $P$, where market demand and supply curves intersect. At the initial instant, no force will be acting to drive market price either up or down. However, if current production at price, $P$, exceeds current consumption at the same price (and there is no reason why this should not be so), aggregate stocks will be increasing, which means that the market demand and supply curves will be shifting over time. ${ }^{1}$ The equilibrium defined by the intersection of the market demand and supply curves at time $t=0$ will be strictly transitory in this case, for market demand will shortly cease to be equal to market supply.

It is apparent that for market equilibrium to occur at any given date 1) excess holder demand must equal zero and 2) excess user demand must equal zero. ${ }^{2}$ Market equilibrium does not imply an absence of "motion" or "change" because individual stock holdings will vary more or less continuously over time. After all, households and businesses may replenish inventories of consumer goods at the end of each week and then run down holding during the course of the week to meet daily requirements. However, in the midst of all these changes, average holdings of inventories and average levels of production, consumption, and trade will be constant from period to period so long as equilibrium prevails.

\footnotetext{
${ }^{1}$ Indeed, only if both producers are each holding exactly their respective desired stocks of inventories will production and consumption coincide with no stock changes.

${ }^{2}$ One may substitute, equivalently, the condition that actual production be equal to actual consumption if production and consumption adjust quickly to desired levels, as seems plausible.
} 


\section{Conclusion}

In the microeconomic portions of principles and intermediate macroeconomics, supply and demand analysis is presented as "the truth." However, the simple Keynesian macroeconomic model virtually ignores market clearing, while the standard microeconomic model of supply and demand assumes perfect market clearing. Since hidden assumptions are a major source of confusion and misunderstanding between economists and the general public, students should be exposed to stock-flow analysis at the intermediate level as a separate or integrated chapter on supply and demand.

\section{REFERENCES}

Ackley, G. "Commodities and Capital: Prices and Quantities," American Economic Review, 73, March 1983, pp. 1-16.

Archibald, G. C.; Lipsey, R. G. "Monetary and Value Theory: A Critique of Lange and Patinkin," Review of Economic Studies, 26, October 1958, pp. 1-22.

Bushaw, D.; Clower, R. Introduction to Mathematical Eionomics, Homewood, IL: Richard D. Irwin, Inc., 1957.

Chase, S. Asset Prices in Economic Analysis, Berkeley, CA: University of California Press, 1963.

Clower, R. "An Investigation Into the Dynamics of Investment," American Economic Review, 44, March 1954, pp. 64-81.

Hadar, J. "A Note on Stock Flow Models of Consumer Bchavior," Quarterly Journal of Economics, 74, May 1965 , pp. 304-9.

Harrison, G. "The Stock-Flow Distinction: A Suggested Interpretation," Journal of Macroeconomics, 2, 2, Spring 1980, pp. 111-28. 